\title{
SMARTWALL: A NEW WEB-BASED PLATFORM FOR THE VALORIZATION OF THE MEDIEVAL WALL OF AVILA
}

\author{
L. J. Sánchez-Aparicio ${ }^{1, *}$, R. Moreno-Blanco ${ }^{2}$, J. A. Martín-Jiménez ${ }^{1}$, P. Rodríguez-Gonzálvez ${ }^{3}$, A.L. Muñoz-Nieto ${ }^{1}$, D. \\ González-Aguilera ${ }^{1}$ \\ ${ }^{1}$ Dept. of Cartographic and Land Engineering, University of Salamanca, Higher Polytechnic School of Avila, Spain - (luisj, \\ joseabula, alumni, daguilera)@usal.es \\ ${ }^{2}$ Dept. of Geography, University of Salamanca, School of Education \& Tourism, Ávila, Spain - raimoreno@usal.es \\ ${ }^{3}$ Dept. of Mining Technology, Topography and Structures, Universidad de León, Ponferrada, Spain - p.rodriguez@unileon.es
}

\section{Commission II, WG II/8}

KEY WORDS: 4D models, Geospatial database, 360 panoramic images, Cultural Heritage, Heritage valorisation, Data fusion

\begin{abstract}
:
As stated the Nara Document on Authenticity and the last Restoration Charter, valorisation of Cultural Heritage sites requires to understand its tangible and intangible values. These values need to be considered as variables that change along the time and space, and they are the result of the interaction between the cultural heritage assets with its history (civilization, societies, etc.). Under this basis, the research project SmartWall attempts to develop a new platform for the valorisation of the Medieval Wall of Ávila, and thus the transmission of its tangible and intangible values to the society. To this end, SmartWall uses an efficient combination between 360 images, 3D/4D models and a geospatial database. This combination provides the following capabilities: i) upgrading the information in real-time, adding, modifying or deleting any type of document; ii) filtering the information in accordance with specific criteria and; iii) managing the information according with different profiles of the user (e.g. expert user, students and tourists). All this information is boosted with a direct link to a 4D model of the Wall, which allows analysing any aspect of the Wall through time. The development and validation of the SmartWall platform was performed in the Alcázar Gate, one of the most emblematic parts of the Medieval Wall of Avila.
\end{abstract}

\section{INTRODUCTION}

Highlighted in the last International Charter of Restoration (Charter of Krakow, 2000), the preservation of Cultural Heritage sites requires not only to design multidisciplinary and scientific proven restoration processes, but also training and educational actions. These actions require social connection through the integration into national systems of education at all levels. Additionally, the diversity of our heritage values, tangible and intangible, which can vary along the time and space (ICOMOS, 1994), requires the involvement of the society. This true involvement will reinforce the value of the cultural heritage site, since the local citizens are often unaware of the connection between the places they live in, and its rich history.

Within this context, 3D visualisation techniques based on Virtual and Augmented Reality (VR/AR) open up a vast field of applications, using new technologies and devices that allow the user to interact with digital objects and navigate through reconstructed scenes (Xiao et al., 2018). For the museum field, the consolidation and implementation of culture and information technology is called Virtual Museum (Kersten et al., 2017). In spite of its definition it is still not fixed, it varies from immersive virtual tours to interactive apps for smartphones and tablets. In Kersten et al. (2014) a virtual tour was generated from the panorama photographs, allowing, as a result, simple and detailed visualisation of a $\mathrm{CH}$ building from the inside and the outside. In Fernandez-Palacios et al. (2017) virtual reality devices were employed to provide not only a simple visualization but also an immersive experience for digitally reconstructed heritage scenario. By means of a Oculus virtual reality visualization headset and a depth sensor, the user can navigate and interact in a complex 3D or 4D (temporal) archaeological scene as well as to have access to digital media contents. In Nocerino et al. (2018) a system to display heterogeneous information is shown. Its web interface allows the user to view historical information, interrogate the project database and visualize specific data. Moreover, 3D models and immersive virtual tours are shown in the local museums.

Under the bases previously shown, it was proposed the research project SmartWall. This project is focused on the development of a novel web-platform devoted to the valorisation of the Medieval Wall of Ávila, being in line also with the sustainable tourism promoted by the 2030 Agenda for Sustainable Development (SDGS, 2015). This platform is focused on the Avila's society, the tourism of the city, scholars and students coming from different disciplines related with the preservation and valorisation of Cultural Heritage. To this end, an efficient combination between 360 images, 4D models and a geospatial database using several web-programming languages (HTML-5, CSS-3, Php, JavaScript and XML) was used.

\section{SMARTWALL: ARCHITECTURE OF THE APPLICATION}

\subsection{Sources of information to understand the tangible and} intangible values of Cultural Heritage sites

Tangible and intangible values in Cultural Heritage implies the interpretation of heterogeneous historical sources of information. These sources are varied, and they often have nonmetric properties (Rodríguez-Gonzálvez et al., 2017). They encompass historical maps; ancient photographs; ancient drawings and sketches; ancient paintings, which represent tilted

\footnotetext{
* Corresponding author
} 
views of non-existing scenarios (especially useful for the height reconstruction of buildings); other historical iconography; written descriptions on ancient texts; indirect geometrical deductions (Figure 1).

a)

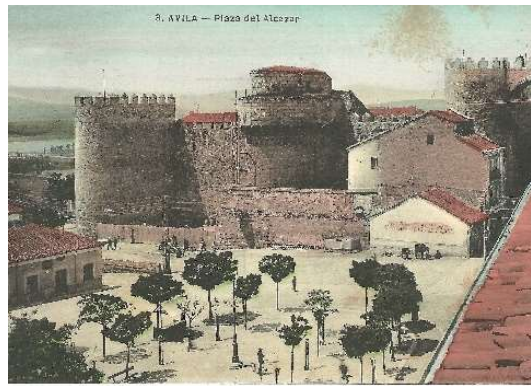

b)

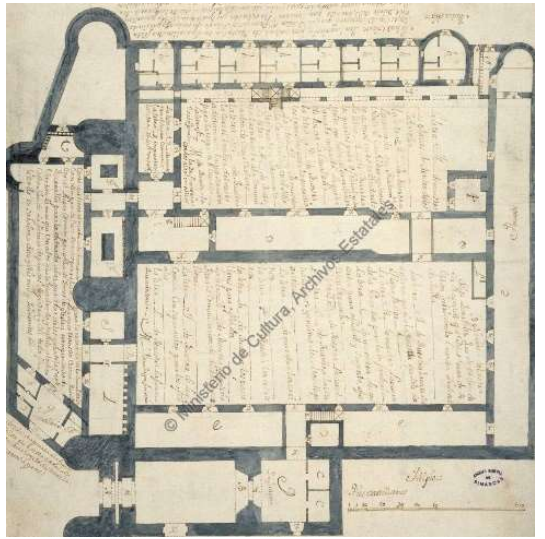

Figure 1. Examples of different types of sources used to feed the platform SmartWall: a) historical photograph used to recreate the status of the Alcázar (citadel) Gate around 1900 and; b) example of technical document about the Alcázar 's plant.

Sources: National Archive of Simancas (Spain)

\subsection{Types of potential users}

Within the context of this SmartWall platform, three different types of users were identified, namely:

Expert users: group of users interested in technical aspects of the Wall (e.g. engineers, architects, archaeologists or art-history students, among others). These users also demand the possibilities of visualizing point clouds to make sections or measurements as well as a 4D viewer to study the evolution of the Wall along the time. Within this group, the information of interest is grouped as follows:

- Past restorations and construction projects: this category stores all that information related with the modifications carried out in the Wall in the past. To this end, the following information should be displayed: i) the author/s of this intervention; ii) a detailed image of the area affected by the intervention; iii) a description of the intervention, highlighting its formal relation with other parts of the Wall and its relation with the Restoration Theories.

- Information about the damages presented on the Wall: this category exhibits all the data related with the damages of the Wall. In this case, the damages are classified in accordance with the typologies defined by the European project HeritageCARE (2017): i) biological colonization; ii) discoloration and deposits; iii) material loss; iv) detachments; v) cracks; vi) deformations and; vi) other type of damages. Also, it is showed information related with the possible origin of this typology of damage as well as a possible way to mitigate it.

- Stratigraphic analysis: within this category is possible to find information related with the stratigraphy of the vertical faces of the Wall. Aditionally it will be highlighted the masonry typologies observed.

- Test results: this information category has the aim of storing all datasets related with the tests carried out on the Wall (e.g. archaeological campaigns or 3D reconstructions). The correct definition of this typology requires the following fields: i) a classification of the test in destructive, minordestructive and non-destructive test and; ii) a short description of the procedure carried out and the outputs obtained.

Non-expert users: this group represents the largest group, so the information need to be explained in a didactical way. Within this group they were identified two sub-groups: i) the tourists and; ii) the scholars.

For the first sub-group, the information is categorized as follows (Figure 2a):

- Information about the current structures: this category shows all the information related with the current structures (e.g. integrated cultural heritage assets). The information will be show following the next structure: i) a title with the name of the asset; ii) a detailed image of the asset; iii) a short description of the asset and its historical relation with the Wall.

- Information about past structures and constructions: in this category is stored all the information related with past structures (e.g. the Alcázar Castle) for which only some traces are visible over the Wall.

- Information about intangible values: this category has the aim of showing information related with past traditions (e.g. the social situation during the Spanish Civil War) and technologies. To this end, SmartWall will show: i) a main image that represent this intangible value; ii) a short description on which is reflected the social situation and/or the technology of the epoch. This information could be complemented by another images that enhances the user experience.

As well as typologies of information previously shown, the user will have access to two more information sources: i) a general description of the Wall and; ii) a detailed description of the area on which the user is located. This type of information has the aim of contextualize the area consulted and thus, to understand its different roles along the time.

Concerning the scholar group, we want highlight that SmartWall is focused on adapt the scientific knowledge to the cognitive development of different ages and to the educational needs of the different stages. In this sense and transversally, the approach would start from the provisions of Spanish educational laws -Real Decreto 126/2014 (2014)- that establish the basic curriculum of Primary Education, for the subject of Social Sciences in Block IV, Las Huellas del Tiempo. Within this part it is highlighted the following sentences: "4. Develop a curiosity to know the forms of human life in the past, valuing the importance of the remains for the knowledge and study of history and cultural heritage to be taken care of bequeathed" and "5.Value the importance of museums, sites and historical monuments as spaces where they teach and learn by showing an attitude of respect for their environment and culture, appreciating the cultural heritage". Thus, playful methodologies based on Gamification, Games Based Learning, etc., would be implemented. Through cartoon avatars scholars 
would do a virtual tour knowing the last remains and structures of the Wall. To penetrate into the Alcazar Castle they should solve questions and process information. In this sense, several levels will be adapted taking into account the contents to be studied in the different academic courses. For example, emphasizing the Roman remains for the fourth-year students; in the medieval construction and its reforms in Modern Era, for the fifth one; or in the new uses and their conservation in the last two centuries for the sixth.

As it was stated before, this way of showing the information will be enhanced with the use of cartoon avatars (Figure $2 b$ ). This graphical resource creates a link between the scholar and the past that allow to improve the involvement of the scholar in the planned activities through empathy.

a)

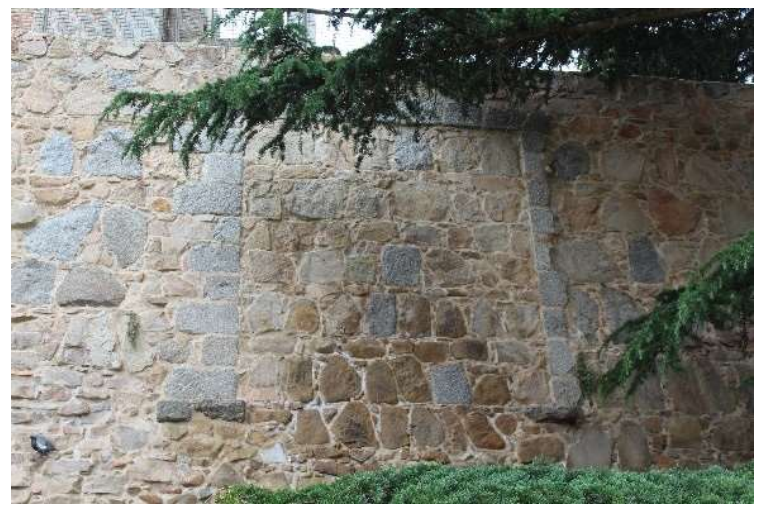

b)

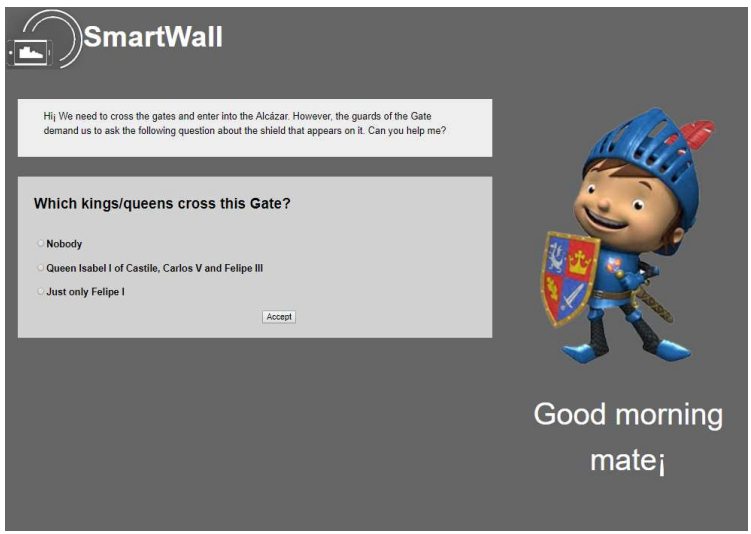

Figure 2. An example of the different areas of interest for a nonexpert user: a) hidden traces of the Alcázar inside the Wall; b) example of the way in which the information can be consult by a scholar, in this image it is possible to see the avatar of SmartWall, presented by a medieval cartoon.

2.3 The management of information: integrating 360 images, historical sources, point clouds and 4D models

As it was highlighted, the valorisation of both Cultural Heritage values requires the development of a platform able to synthetize the vast and heterogenous information about the Wall. As well as to show the information with different types of languages, from technical languages in case of expert users to didactical languages in case of tourists or scholars. According with this, SmartWall will be supported by the latest advances in 360 images, web-based languages (HTML, CSS, PHP and JavaScript) and rendering engines (Figure 3). Regarding the last one, two different viewers are used by SmartWall. On the one hand the open source library Potree (Schütz, 2016) for the rendering of point clouds (e.g. point clouds result of archaeological campaigns). This library was chosen due to the capacity of rendering large point clouds, making measures and sections as well as introducing texts and images in form of annotations. On the other hand it is used the 4D viewer developed by Rodríguez-Gonzálvez et al. (2019). This engine allows to render the Wall along the time, using to this end the architectural scenarios modelled by Rodriguez-Gonzálvez (2019; 2018). To this end, the user has a timeline bar at the bottom of the interface that allow to change the epoch render by the viewer. In addition it is possible to integrate text and images by means of the use of $3 \mathrm{D}$ hotspots, allowing to improve the transfer of intangible values such as traditions that normally are present in photos (Rodríguez-Gonzálvez et al., 2019).

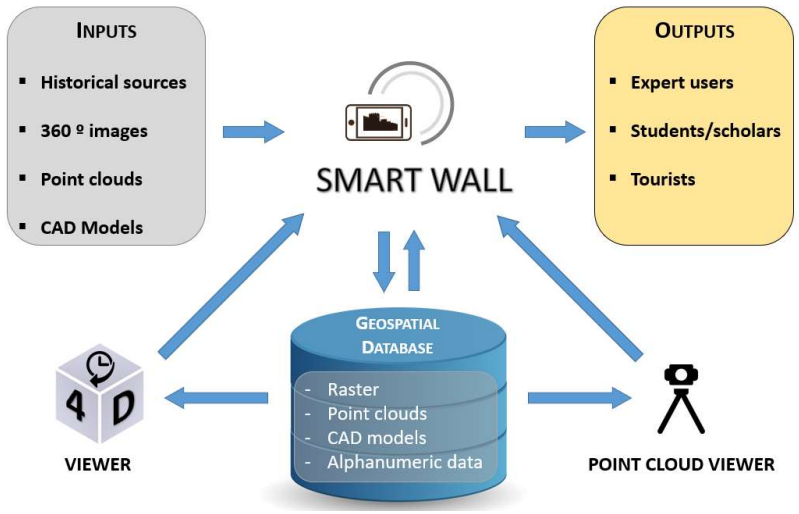

Figure 3. Flowchart of the SmarWall platform and main engines: 360 images, web-based languages, the open-source library Potree, a 4D viewer and a geospatial database.

All the features previously shown are complemented by means of a geospatial database. This element is made up by several tables that allow to store and organize the different available data. Example of this can be found in the table of damages. This table stores all the damages detected on the Wall, their categories, descriptions, possible origins, consequences and ways to mitigate them. Moreover, all the information stored in the database is geolocalized by means of the latitude and longitude coordinates within the panorama. Another relevant role of the geospatial database is the possibility of making queries. This functionality makes possible to filter the information in accordance with several criteria (e.g. filtering the restoration projects by year or the damages by category), improving the user experience.

\subsection{Platform's GUI}

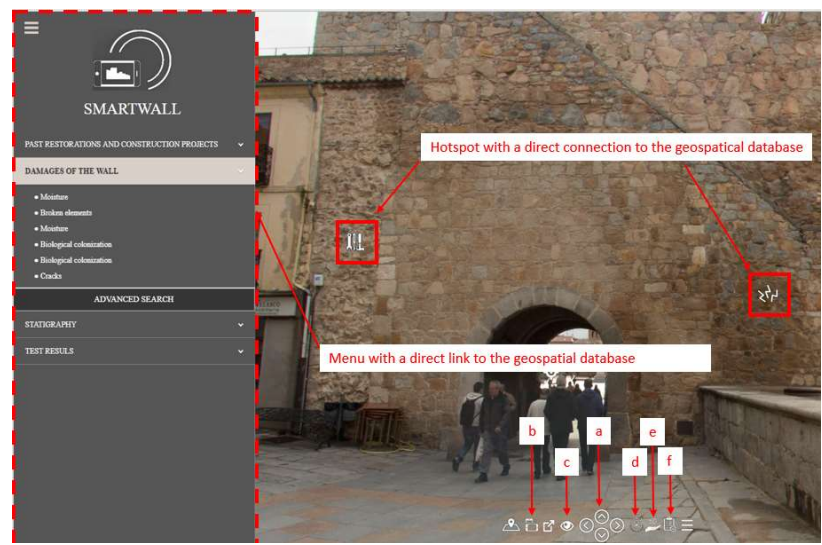

Figure 4. Disposition of the main components of the platform. 
The integration of 360 images, historical sources, point clouds and $4 \mathrm{D}$ models with the geospatial database required the creation of a GUI made up by two bodies (Figure 4): i) one body, placed at the left of the application, devoted to shown the results of the geospatial database in form of labels and; ii) a second body on which panoramic images and 4D models are showed. It is worth mentioning that the second body (area where the graphic information is plotted) is surrogated to the first body. Thanks to this subrogation, when the user clicks on a label the platform gets the panorama and the label position (expressed in tilt and pan coordinates) and goes to the places on which the information is.

Complementary the two bodies previously explained, SmartWall integrates a custom menu focused on providing the best user experience (Figure 4). To this end, the following buttons are included: i) buttons devoted to the navigation along the panoramas (a); ii) a button to activate/deactivate the gyroscope (b); iii) a button to show/hidden specific hotspots (c); iv) a button to run the $4 \mathrm{D}$ viewer (d); v) a button to render the Wall's point cloud (e) and; a button to show the information of the area consulted (f).

Besides all this, SmartWall GUI includes several APIs that improves the user experience, namely: i) a gyroscope API and ii) a geolocation API. The first API allows to capture the data coming from the device's gyroscope, synchronizing the movement of the table or smartphone, by means of the data coming from the accelerometers, with the point of view of the panoramic images. This functionality generates an immersive sensation in the user (Figure 5a). On the other hand, the geolocation API allows to initialization the application in the nearest panorama.

a)

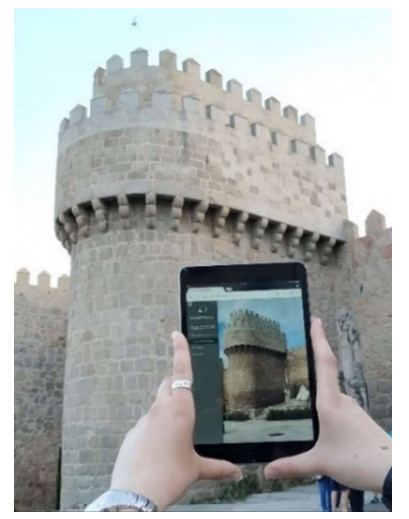

b)

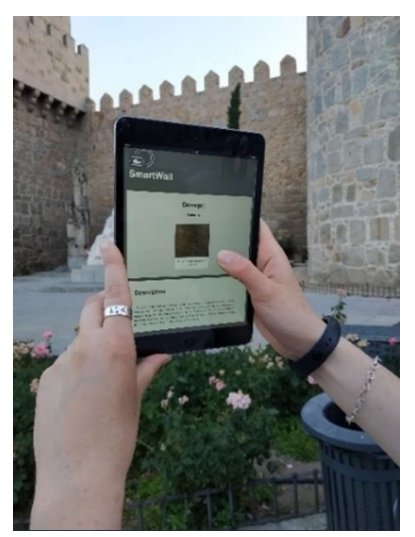

Figure 5. Performance of the SmartWall when an expert user consults a moisture on the Alcázar's homage tower: a) automatic alignment between the user and the homage tower thanks to the gyroscope API and; b) appearance of the platform when the expert user clicks on the damage.
The information of the platform could be consulted by the user through the use of the so-called hotspots. When the user clicks on one of them, the platform makes a query to the database and plot the demanded information, which depends on the type of user, by means of a HTML web-page (Figure 5b).

\section{THE MEDIAEVAL WALL OF AVILA}

In its present configuration and appearance, the wall of Avila has its origin in the reign of Alfonso VI and, therefore, in the framework of the conflicts between christians and muslims for the dominion of the Meseta. After the seizure of Toledo in 1085 , territories known as the Castilian extremes passed into their possession, which were repopulated and revitalized. This process was entrusted to Raimundo de Borgoña, son-in-law of the monarch, who would take care of the reorganization of Avila, Segovia and Salamanca. In the case of Avila, according to the vestiges preserved in some of the eastern side towers, it seems that at first a wall of quadrangular towers was built or rebuilt, the vestiges of which are visible at the doors of the Alcazar and San Vicente and in the southern side of the Homage Tower, although its full perimeter has not yet been defined. It would be later, already during the second half of $s$. XII, when the current wall was built with the physiognomy we know. In this sense, we must remember that, in addition to the struggles between christians and muslims, from 1150 to 1237 the kingdoms of Leon and Castile remained separate and sometimes also in conflict.

a)

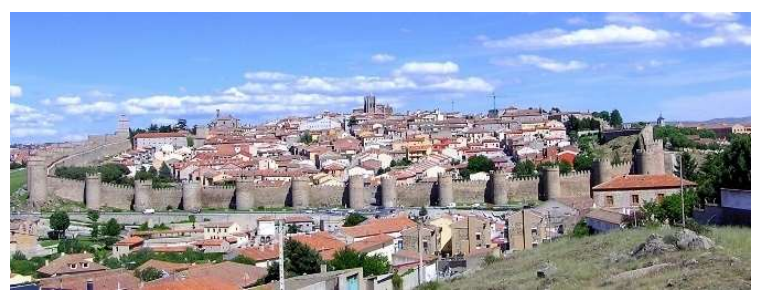

b)
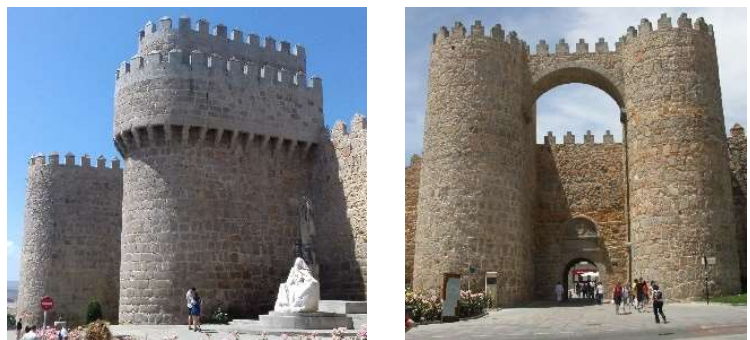

Figure 6. Medieval wall of Avila: a) general view and; b) detailed views of the Alcázar Gate. In these photos it is possible to observe a great variety of signs related with the tangible values of the Wall (e.g. marked restorations) and intangible values (e.g. the social/economic situation that evokes the shield placed on the entrance).

A quick description of the monument would indicate that it draws a perimeter of something more than $2.5 \mathrm{~km}$ (Figure 6), towards the rectangular, with its larger sides to the north and south, which has nine doors and three little exits; and that its construction is homogeneous. However, leaving aside the unifying restorations of style undertaken in the late nineteenth and early twentieth centuries especially, we discover a construction that is not as uniform as it seems. The route is arranged supporting the parent rock-North and South-taking materials both on site and reused. Pieces of ashlar masonry are included in the corners and arches, with the walls and towers 
being erected based on two panels composed mostly of large pieces of masonry carved with mirrors whose rows are laid on gravel strips. Among them a soul of mortar and / or rammed earth following a constructive system frequent in medieval architecture. This wall completes the walkway, on which the parapet rises towards the interior and the crenellated wall towards the exterior. The brick is used as the only decorative concession, basically forming friezes of corner posts in the tops of some towers. Despite what today can transmit its physiognomy, it is clear that it was not just a passive defence system. To the high walls were added holes for throw objects in different sides; there was a barbican gifted with locations to shoot before the oriental side that reinforced the defence of the most vulnerable side, the only one that opens onto a plain; probably also on this side there was a moat; to which the artillery power of the cathedral cimorro in its last configuration would be added. On the other three fronts, the presence of the river to the west acting as a natural moat, and the unevenness of the terrain and rocky escarpments to the North and South made further fortification unnecessary.

\subsection{The Alcázar Gate}

This Gate is, together with that of San Vicente, the most powerful and representative of the wall of Avila (Figure 3b). At the time, both have been the most used by the population, since they communicated the high areas of the city and given the steep orography that gave access to the rest. These doors remind us of the structure of the towering weswerke of the Carolingian temples, as Gutierrez Robledo (2009) has pointed out. Uniting its towers -converging axis in the Alcázar Gate- flies a bridge in the middle of a canyon that unites them and facilitates communication, the movement of troops and, if necessary, facilitates harassment on the back of the enemy that manages to approach the access door. Gómez-Moreno (2002) pointed out that these are unique examples in the technique of his time. Its complex defence system was completed with plywood doors that avoided the possibility of being burned, a rake that descended inside the tunnel, a zenith opening to throw all kinds of elements, gaps in the sides to bet defenders at street level and doorways in the inner side. A shield was placed on its arch in the 1590s that had previously been in the Town Hall building stamped with the coat of arms of the Catholic Monarchs, to which was added an inscription alluding to the repairs carried out in the Alcázar under the direction of Francisco de Mora. Finally, an open space was added on the inside as a small square in which the enemy who managed to enter was unguarded.

Historically, the Alcázar Gate has been the most representative door of the city. Before it, the most illustrious visitors were received in Avila and penetrated through it. Thus, it is recorded that on June 2, 1475 Queen Isabel I of Castile made her entry through this door, and there confirmed the privileges that already had the city. Likewise, we also know that in June of 1534 Carlos V was brought in litter to Ávila, entering the city through it, passing through the Alcázar and being driven to the cathedral. There, the warden of the fortress gave him two golden keys in a silver fountain, the Alcázar and the dome of the main church as a sign of possession, and he returned them to him so that he could have them in his name. Then, Carlos V swore the rights, privileges and freedoms of the city. Something similar happened in 1600 on the occasion of the visit to the city of Felipe III and Margarita of Austria (2007).

\subsubsection{Information sources}

As was pointed out in 2.1. information sources for the documentation of $\mathrm{CH}$ assets, in general terms, are heterogeneous. For a deep knowledge of the surroundings of the Alcázar and the Gate associated with it have been used multiple sources. Among them, the main one was a detailed analysis of the construction, with special attention to those elements that could indicate different construction phases or provide relevant information of another kind (Figure 3b). Likewise, a thorough work has been done to review the existing bibliography and graphic sources -drawings, engravings and old photographs-, as well as the numerous restoration projects carried out in this area.

\section{EXPERIMENTAL RESULTS}

\subsection{Virtual environment}

For the creation of the virtual environment, made up by the 360 images, a total of 35 spherical panoramas were necessary. These panoramas were created with the open-source software Hugin (http://hugin.sourceforge.net/) and introduced into a virtual environment with the low-cost software Pano2VR (http://Pano2VR.com). The GUI of the platform as well as its integration with the point cloud rendering engine and the 4D viewer were carried out through the use of an in-house plugin for Pano2VR.

Regarding the point cloud viewer, it was considered as the base model the point cloud created by Mancera-Taboada et al. (2010). This point cloud was georeferenced in ETR-89 and is made up by $73,876,532$ points. With respect to the $4 \mathrm{D}$ visualization, the current version of the platform SmartWall includes the diachronic reconstruction carried out by RodríguezGonzálvez et al. $(2019 ; 2018)$. These reconstructions were focused on the Alcázar and on some extramural buildings which disappeared I 1882 and 1930.

\subsection{Consulting the information for a PhD student (expert user)}

If the platform was initialized by an expert user the information plotted, in form of hotspots, will be the following one: i) past restorations and construction projects; ii) information about the damages presented on the Wall; iii) stratigraphic analysis and; iv) test results. This information will be also visualized in the right body of the interface (Figure 7). Within each information label the user could make queries to the database, allowing the filtering of information. For example, if this user wants to consult only those damages related with the biological colonization it is necessary to make an advanced search inside the field damages and filter the information by class of damage (Figure 7a).

a)

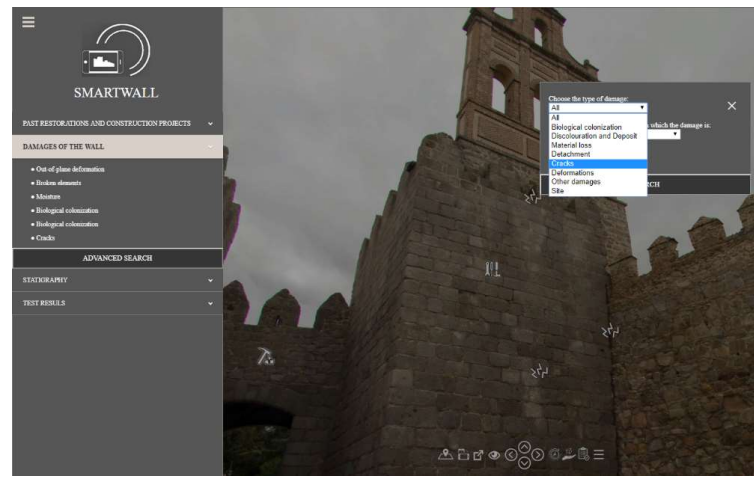


b)
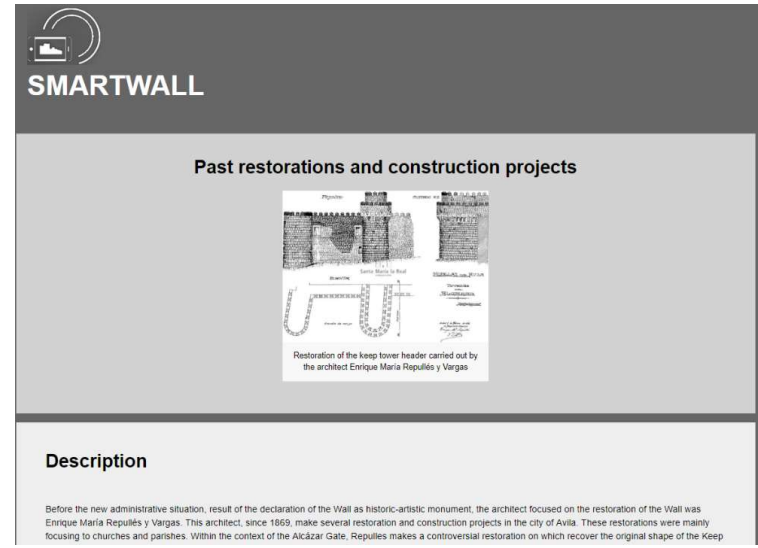

Figure 7. Interface of the platform SmartWall when an expert user interacts with it for: a) making a query to the database to filter the damages of the Wall by class of damage; $b$ ) and c) consulting the restoration works carried out by the architect

Enrique $\mathrm{M}^{\mathrm{a}}$ Repullés y Vargas on the Alcázar Gate.

The link to the $4 \mathrm{D}$ viewer included within the modal page of the restoration action consulted, allows to evaluate the header of the homage tower before the intervention and deduce the criteria, as well as the restoration theory, followed by the architect (Figure 8).

a)

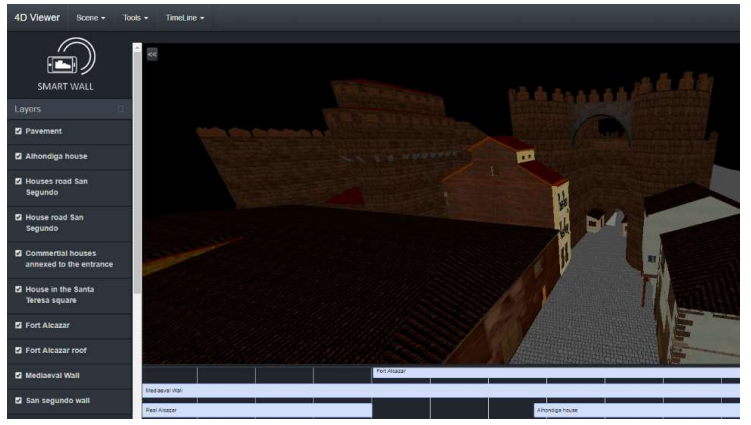

b)

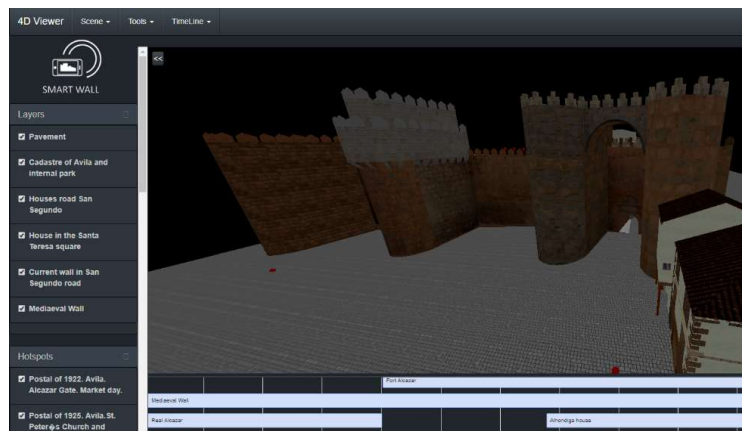

Figure 8. Appearance of the homage tower before and after the intervention of the architect Enrique $\mathrm{M}^{\mathrm{a}}$ Repullés y Vargas.

\subsection{The interaction between a tourist and the platform SmarWall}

If SmartWall is consulted by a tourist, the information plotted will be completely different. Instead of using a technical language, the platform will change to a didactical one on which the main fields, represented in form of hotspots, are those exposed in Section 2.3, if the user wants information about the intangible values of the platform (e.g. the market day next to the Alcáraz) it is enough with clicking in the right menu in Market day in Avila and the platform will be place automatically on the position on which this hotspot is placed (Figure 9a). Then, the user will click on it and could consult the information related with this past tradition (Figure 9b). Within this HLM page, the platform SmartWall will have a link to the $4 \mathrm{D}$ viewer, making possible to travel to the epoch on which this tradition takes place (Figure 10)

a)

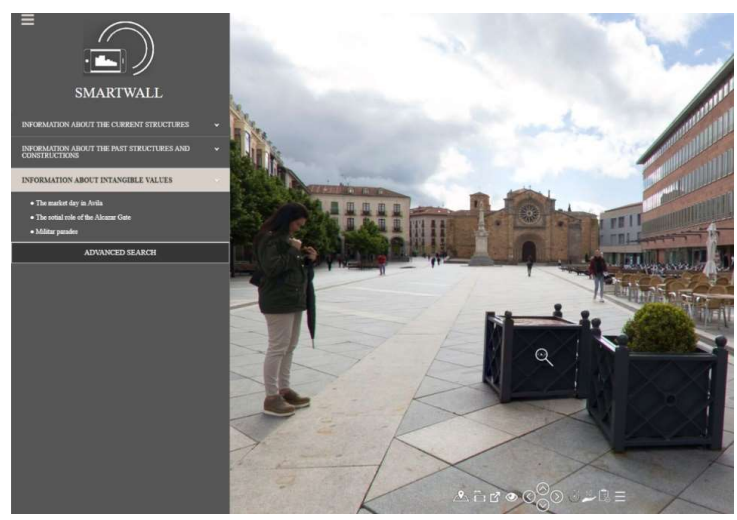

b)
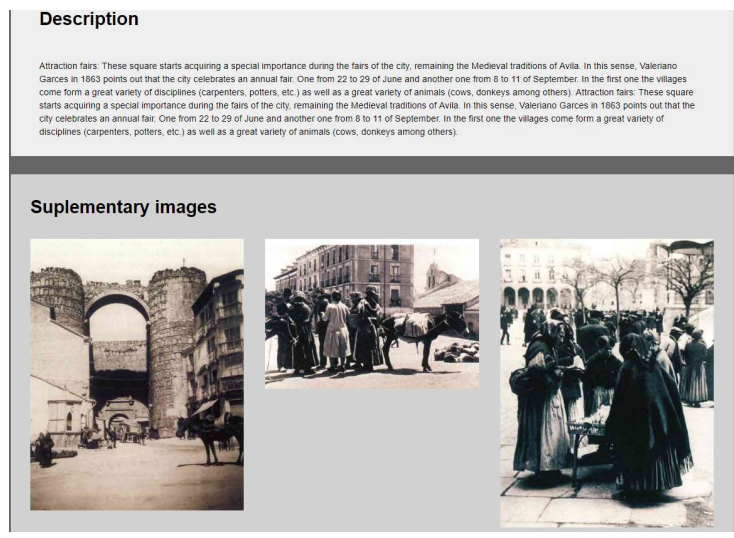

Figure 9. Response of the platform when a tourist wants to consult the information related with the Market day.

a)

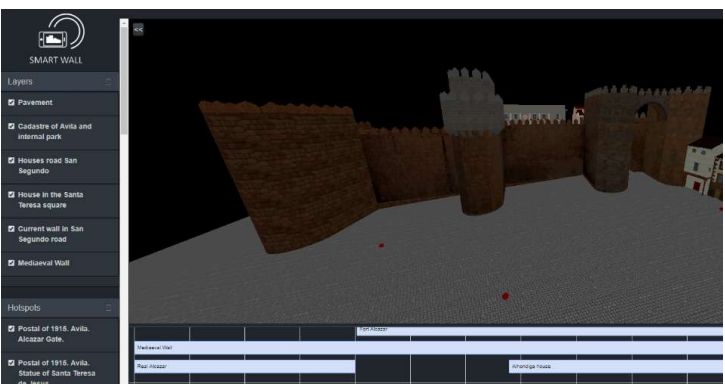

b)

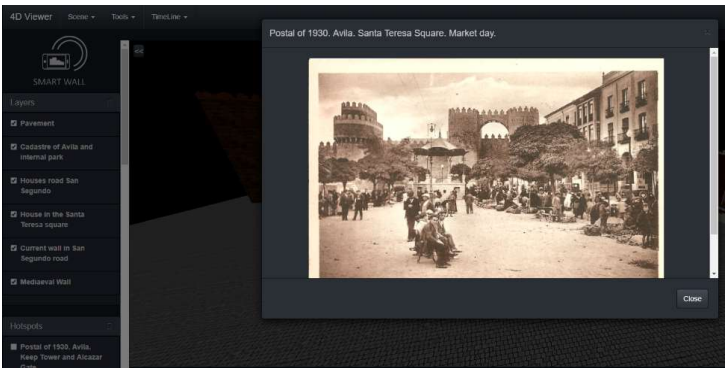

Figure 10. Result of the 4D viewer when the user consults the information related with the Market day: a) general view of Alcázar Gate in 1930; and b) result of consulting a 3D hotspot related with the market day. 


\subsection{Performance of the platform when is consulted by a scholar}

Finally, if SmartWall is consulted by ten-year-old student, the platform automatically opens a didactical environment, in form of a game, focused on the Medieval Age (epoch studied by this type of students at the primary school). During this game, the platform will ask several questions, through a cartoon avatar, related with the past history of the Gate (Figure 2b) (Figure 11a). Each time that the student passes the quiz, the platform will open the next stage until the student finish the planned path. In the case of the didactical environment planned for the Alcázar Gate (called The Alcázar game) (Figure 12), the final stage requires a direct interaction between the present and the past. To this end, the platform will ask for the keys of the Alcázar in order to close the Gate to the enemies. These keys are placed on the corner window of the Medieval Alcázar. To solve this problem, the student will consult the 4D model on which is highlighted this window (Figure 11). After that, the student will go to the place on which was positioned this window and would relate the current sings of the Wall (Figure $2 \mathrm{a}$ and Figure 12) with the presence of an ancient fortification (Figure 11).

a)

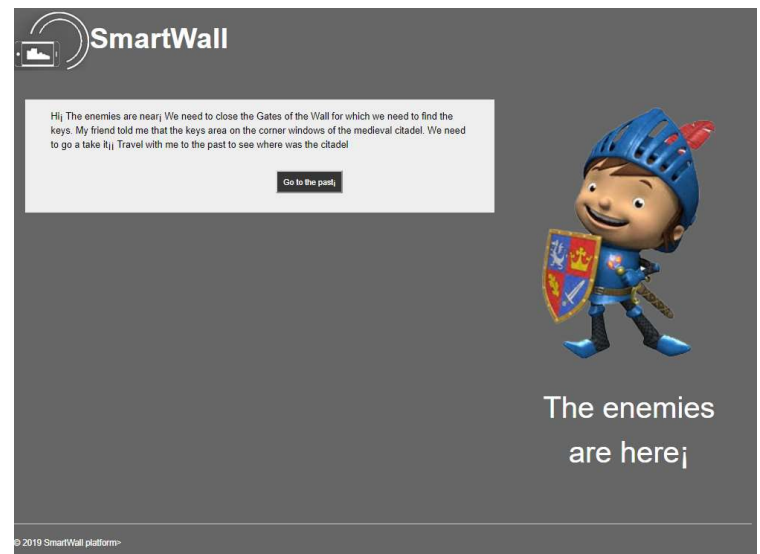

b)

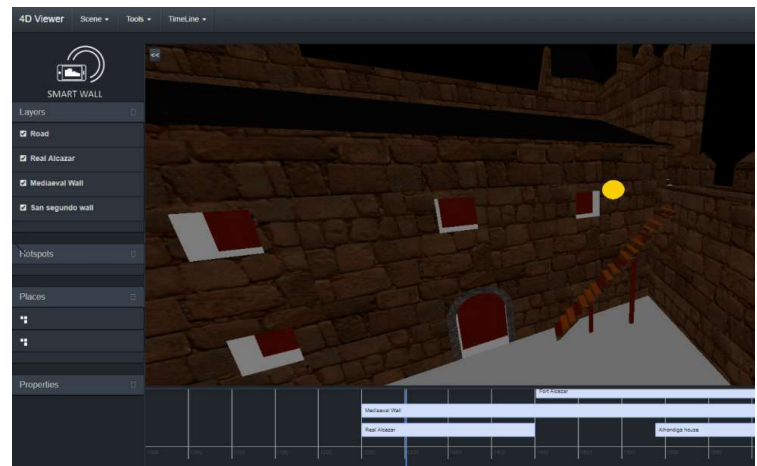

Figure 11. Role of the diachronic reconstructions in the education of scholars: a) HTML page that appears when the scholar is in the final stage of the game and; b) appearance of the 4D viewer highlighting the area on which is placed the key and is related with the visible sign presented nowadays on the Wall.

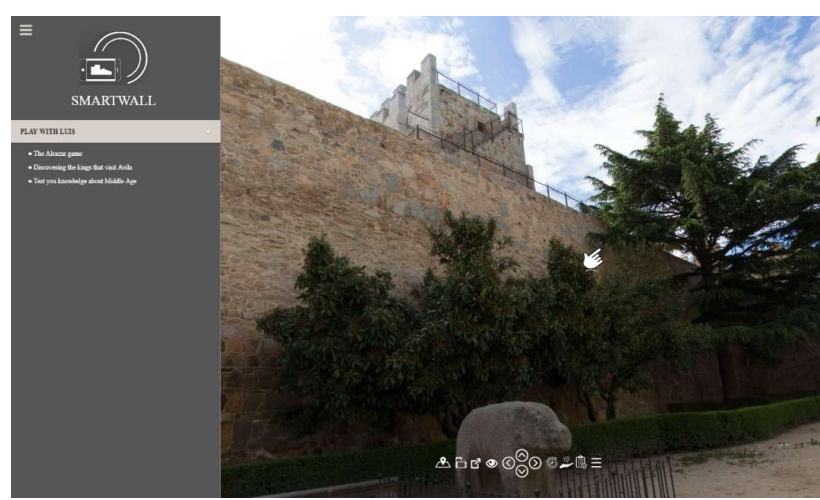

Figure 12. Aspect of the platform SmartWall when the child finds the window on which is placed the key. Once the scholar clicks on it the game ends, showing a brief description of the Alcázar and its role along the time.

\section{CONCLUSIONS}

This work shows the results obtained within the framework of the research project SmartWall. This project is devoted to develop a web-based platform of the medieval wall of Avila able to transfer the tangible and intangible values of this monument to the society. This transfer is possible thanks to the efficient combination of historical sources, 360 images, webbased languages, a geospatial database and several render engines. Due to the great diversity of users, from expert users to scholars, a great effort has been made in the plotting of these values, using to this end technical as well as didactical languages, within a normalized HTML structure.

Future improvements of the platform will be focused on adding new scholar profiles (the current version includes only primary students) as well as a new interface able to visualize and consult the immersive tour and the 4D models by means of VR devices such as the Oculus or the Unotec glasses. Regarding the diachronic reconstructions, new models will be created with the aim of feeding the $4 \mathrm{D}$ viewer with a wide range of ages.

\section{ACKNOWLEDGEMENTS}

This work has been financed by the research grant "Investigación de Temas abulenses, 2018" granted by the institution Gran Duque de Alba. First author would like to thank the University of Salamanca for the program for human resources "Programa II: Contratos Postdoctorales".

\section{REFERENCES}

Cátedra, M., de Tapia, S., 2007. Para entender las murallas de Ávila, Ámbito Ediciones, Valladolid.

Charter of Krakow, 2000. Principles for conservation and restoration of built heritage http://smartheritage.com/wpcontent/uploads/2015/03/KRAKOV-CHARTER-2000.pdf (25 June 2019).

BOE, 2014. Real Decreto 126/2014, de 28 de febrero, por el que se establece el currículo básico de la Educación Primaria. Boletín Oficial del Estado 52, 19349-19420. https://www.boe.es/buscar/pdf/2014/BOE-A-2014-2222consolidado.pdf (25 June 2019). 
Fernández-Palacios, B.J., Morabito, D., Remondino, F., 2017. Access to complex reality-based 3D models using virtual reality solutions. Journal of cultural heritage, 23, pp. 40-48.

Gómez Moreno, M., 2002. Catálogo monumental de la provincia de Ávila, Institución Gran Duque de Alba, Avila, Spain.

Gutierrez Robledo, J.L., 2009. Las murallas de Avila: arquitectura de historia, Institución Gran Duque de Alba, Avila, Spain.

HeritageCARE project, 2017. Survey of construction systems, type of damages and deterioration processes within the SUDOE territory http://heritagecare.eu/results/deliverables/\# (25 June 2019)

ICOMOS, 1994. The Nara document on authenticity. https://www.icomos.org/charters/nara-e.pdf (25 June 2019).

Kersten, T.P., Hinrichsen, N., Lindstaedt, M., Weber, C., Schreyer, K., Tschirschwitz, F., 2014. Architectural historical $4 D$ documentation of the old-segeberg town house by photogrammetry, terrestrial laser scanning and historical analysis. Springer, London, pp. 35-47.

Kersten, T.P., Tschirschwitz, F., Deggim, S., 2017. Development of a virtual museum including a 4D presentation of building history in virtual reality. In: ISPRS Archives of Photogrammetry, Remote Sensing and Spatial Information Sciences, Nafpio, Greece, Vol. XLII-2/W3, pp. 361-367, doi.org/10.5194/isprs-archives-XLII-2-W3-361-2017.

Mancera-Taboada, J., Rodríguez-Gonzálvez, P., GonzálezAguilera, D., Muñoz-Nieto, Á., Gómez-Lahoz, J., HerreroPascual, J., Picón-Cabrera, I., 2010. On the use of laser scanner and photogrammetry for the global digitization of the medieval walls of Avila. In: IAPRS, Saint-Mandé, France, Vol. XXXVIII/Part 3A, pp. 169-174.

Nocerino, E., Menna, F., Toschi, I., Morabito, D., Remondino, F., Rodríguez-Gonzálvez, P., 2018. Valorisation of history and landscape for promoting the memory of WWI. Journal of Cultural Heritage, 29, pp. 113-122.

Rodríguez-Gonzálvez, P., Guerra Campo, Á., Muñoz-Nieto, Á.L., Sánchez-Aparicio, L.J., González-Aguilera, D., 2019. Diachronic Reconstruction and Visualization of Lost Cultural Heritage Sites. ISPRS International Journal of GeoInformation, 8 (2): 61.

Rodríguez-Gonzálvez, P., Mamani, S.C., Campo, A.G., Sánchez-Aparicio, L.J., del Pozo, S., Muñoz-Nieto, A., González-Aguilera, D., 2018. Diachronic reconstruction of lost cultural heritage sites. Study case of the medieval wall of Avila (Spain). In: ISPRS Archives of the Photogrammetry, Remote Sensing \& Spatial Information Sciences, Riva del Garda, Italy, Vol. XLII-2, pp. 975-981, doi.org/10.5194/isprs-archives-XLII2-975-2018.

Rodríguez-Gonzálvez, P., Muñoz-Nieto, A.L., del Pozo, S., Sanchez-Aparicio, L.J., Gonzalez-Aguilera, D., Micoli, L., Barsanti, S.G., Guidi, G., Mills, J., Fieber, K., 2017. 4D Reconstruction and visualization of Cultural Heritage: Analyzing our legacy through time. In: ISPRS Archives of the Photogrammetry, Remote Sensing \& Spatial Information
Sciences, Nafpio, Greece, Vol. XLII-2/W3, pp. 609-616, doi.org/ 10.5194/isprs-archives-XLII-2-W3-609-2017.

Schütz, M., 2016. Potree: Rendering large point clouds in web browsers

https://www.cg.tuwien.ac.at/research/publications/2016/SCHU ETZ-2016-POT/SCHUETZ-2016-POT-thesis.pdf (25 June 2019).

SDGS, 2015. Transforming our world: the 2030 Agenda for Sustainable Development https://sustainabledevelopment.un.org/post2015/transformingou rworld (25 June 2019).

Xiao, W., Mills, J., Guidi, G., Rodríguez-Gonzálvez, P., Barsanti, S.G., González-Aguilera, D., 2018. Geoinformatics for the conservation and promotion of cultural heritage in support of the UN Sustainable Development Goals. ISPRS journal of photogrammetry and remote sensing, 142, pp. 389-406. 